\section{(- OPEN ACCESS}

\title{
Tackler's head position relative to the ball carrier is highly correlated with head and neck injuries in rugby
}

\author{
Shogo Sobue, ${ }^{1}$ Takayuki Kawasaki, ${ }^{1}$ Yoshinori Hasegawa, ${ }^{1}$ Yuki Shiota, ${ }^{1}$ Chihiro Ota, ${ }^{2}$ \\ Takeshi Yoneda, ${ }^{2}$ Shigeyuki Tahara, ${ }^{2}$ Nobukazu Maki, ${ }^{3}$ Takahiro Matsuura, ${ }^{3}$ \\ Masahiro Sekiguchi, ${ }^{3}$ Yoshiaki Itoigawa, ${ }^{4}$ Tomohiko Tateishi, ${ }^{5}$ Kazuo Kaneko ${ }^{1}$
}

\begin{abstract}
- Additional material is published online only. To view please visit the journal online (http://dx.doi.org/10.1136/ bjsports-2017-098135)
\end{abstract}

${ }^{1}$ Department of Orthopaedic Surgery, Faculty of Medicine, Juntendo University, Tokyo, Japan

${ }^{2}$ Rugby Football Club, Keio University, Yokohama, Japan ${ }^{3}$ Rugby Football Club, Meiji University, Tokyo, Japan ${ }^{4}$ Department of Orthopedic Surgery, Juntendo University Urayasu Hospital, Chiba, Japan ${ }^{5}$ Department of Sports and Arthroscopy Center, Doai Memorial Hospital, Tokyo, Japan

\section{Correspondence to} Dr Takayuki Kawasaki, Department of Orthopaedic Surgery, Juntendo University Faculty of Medicine, Bunkyo, Tokyo 113-8421, Japan; k-saki@luck.ocn.ne.jp

Accepted 30 October 2017 Published Online First 21 November 2017
Check for updates

To cite: Sobue $S$, Kawasaki T, Hasegawa Y, et al. Br J Sports Med 2018;52:353-358

\section{ABSTRACT}

Objectives To characterise the tackler's head position during one-on-one tackling in rugby and to determine the incidence of head, neck and shoulder injuries through analysis of game videos, injury records and a questionnaire completed by the tacklers themselves. Methods We randomly selected 28 game videos featuring two university teams in competitions held in 2015 and 2016. Tackles were categorised according to tackler's head position. The 'pre-contact phase' was defined; its duration and the number of steps taken by the ball carrier prior to a tackle were evaluated.

Results In total, 3970 tackles, including 317 (8.0\%) with the tackler's head incorrectly positioned (ie, in front of the ball carrier) were examined. Thirty-two head, neck or shoulder injuries occurred for an injury incidence of $0.8 \%(32 / 3970)$. The incidence of injury in tackles with incorrect head positioning was $69.4 / 1000$ tackles; the injury incidence with correct head positioning (ie, behind or to one side of the ball carrier) was 2.7/1000 tackles. Concussions, neck injuries, 'stingers' and nasal fractures occurred significantly more often during tackles with incorrect head positioning than during tackles with correct head positioning. Significantly fewer steps were taken before tackles with incorrect head positioning that resulted in injury than before tackles that did not result in injury.

Conclusion Tackling with incorrect head position relative to the ball carrier resulted in a significantly higher incidence of concussions, neck injuries, stingers and nasal fractures than tackling with correct head position. Tackles with shorter duration and distance before contact resulted in more injuries.

\section{INTRODUCTION}

Rugby is a collision sport in which players incur many more injuries of the head, neck and shoulders than in other sports. ${ }^{1-3}$ Serious injuries such as spinal cord trauma sometimes occur. ${ }^{4}$ According to an epidemiological study, severe injuries often occurred in the scrum prior to 2000; however, the incidence of these injuries has greatly decreased as a result of rule amendments backed by biomechanical research on player safety. ${ }^{5-8}$ Concussions, neck injuries, stingers and shoulder injuries occur most commonly during tackling. ${ }^{19-13}$ Although many studies have investigated sports safety equipment such as mouthguards, headguards and shoulder pads, the actual effects of this equipment remain controversial. ${ }^{10}{ }^{14-16}$ During play, the ball carrier is protected from high tackles and stiff-arm tackles according to the rules of the game, ${ }^{17}$ because these tackles can potentially cause serious injuries. However, tacklers are merely protected by their tackling skill. ${ }^{18}$ Several attempts have been made to prevent injuries during tackling, including specific tackle technique and preventive exercises; however, no prevention strategy has been established. ${ }^{18}{ }^{19}$ In football, head-down contact and spearing increase the risk of cervical spine injury. Therefore, football rules, education and coaching have been altered to dramatically reduce these incidents. ${ }^{20}$ However, in rugby there are no reports on the relationship between injury incidence and the tackler's head position. World Rugby, the New Zealand Rugby Union and the Australian Rugby Union recommend as a key point that the tackler's head be positioned behind or to one side of the ball carrier during a tackle ${ }^{21-23}$; this technique protects the head and neck from direct impact. However, injuries continue to occur in tacklers who use incorrect head position, with the tackler's head in front of the ball carrier at the time of contact. Several recent studies have used video recordings of games to analyse head placement ${ }^{182425}$; however, the relationship between the incidence of injury and the tackler's head position remains uninvestigated.

The purpose of this epidemiological study was to identify the tackler's head position during one-on-one tackling and to study the incidence of head, neck and shoulder injuries with the aid of game video analysis, injury records and questionnaires completed by the actual tacklers. We hypothesised that the incidence of injury depends on the tackler's head position relative to the ball carrier and that proper tackle techniques can greatly reduce the risk of injury.

\section{METHODS}

This cross-sectional study was conducted to elucidate the incidence of injuries according to the tackler's head position. Two university teams with which the authors are affiliated that reached the semifinals of a national tournament were recruited for study participation. The sample size was determined by statistical power calculations. Our pilot study indicated that incidences of injury were 0.001 and 0.03 for the tackles with correct and incorrect head positioning, respectively. Thus, to detect a clinically meaningful difference in incidence of injury, at least 2170 and 217 events (ie, tackles) were required in each group to achieve $80 \%$ power at alpha $=0.05$. Therefore, a total of over 3000 events were included in the study. We randomly chose 28 videos of games in which these 
teams competed in the 2015 and 2016 seasons. The tackles were categorised and counted according to the tackler's head positions (detailed below). Furthermore, we defined the 'pre-contact phase' (detailed below); the duration of this phase and the number of steps taken by the ball carrier were measured to determine the context of tackle occurrences. Players who tackled with incorrect head positioning were asked to complete our questionnaire (see the online supplementary appendix) while watching a video of the tackle within 1 week after the match. The survey included questions about anthropometric data, years of experience playing rugby, player position, whether the tackle was performed intentionally and the reason for performing the tackle the way they did. The injury records of each team as recorded by the team physiotherapist or doctor were also used for reference.

Injury definitions were consistent with the 2007 consensus statement of the International Rugby Board (known as World Rugby since 2014). ${ }^{26}$ The primary injury definition used was for time-loss injuries, which are defined as a physical insult that occurs during rugby training or play that results in a player being unable to take full part in future rugby training or match play for longer than 24 hours. In this study, we focused on head, neck and shoulder injuries. Additionally, all stinger episodes were counted, even when subjective symptoms diminished within 24 hours, ${ }^{27}$ because the main purpose of the present study was to investigate the precise incidence of injury-related tackles. A player incurring two injuries from one tackle was counted as one player, but both injuries were counted.

The players and their team staff received a thorough explanation of the study and provided their informed consent to participate.

\section{Definition of tackles and precontact phase}

Participants were involved in one-on-one tackles in the game. A tackle was defined according to the report of Quarrie and Hopkins ${ }^{28}$ as occurring when a ball carrier was contacted (hit and/or held) by an opponent, regardless of whether they went to the ground. Tackle incidents were categorised according to the tackler's head position. The first category included tackles with correct head positioning, meaning that the tackler's head was behind or to one side of the ball carrier (figure 1A). The second category included tackles with incorrect head positioning, meaning that the tackler's head was in front of the ball carrier at the time of contact (figure 1B,C-F). More figures in detail are also available in online supplementary figure 1.

To investigate the circumstances surrounding tackles with incorrect head positioning, we measured the duration of ball possession before the tackle and the number of steps the ball carrier took in that time (an approximation of the distance). The precontact phase represented the time and spatial factors of the tackler seeing, recognising and acting on (tackling) the ball carrier.

\section{Statistical analysis}

First, two researchers randomly watched 5 of the 28 game videos (19.2\%) to determine the accuracy of tackle categorisation. The percentage of agreement for inter-rater reliability and kappa coefficient for categorising tackles were explored. Other games were evaluated individually.

The primary analysis used the $\chi^{2}$ test to compare the incidence of head, neck and shoulder injuries between the two types of tackles. The incidence was calculated as the number of injuries per 1000 tackles. ${ }^{28}$ In the $\chi^{2}$ analysis, the Fisher's exact test was
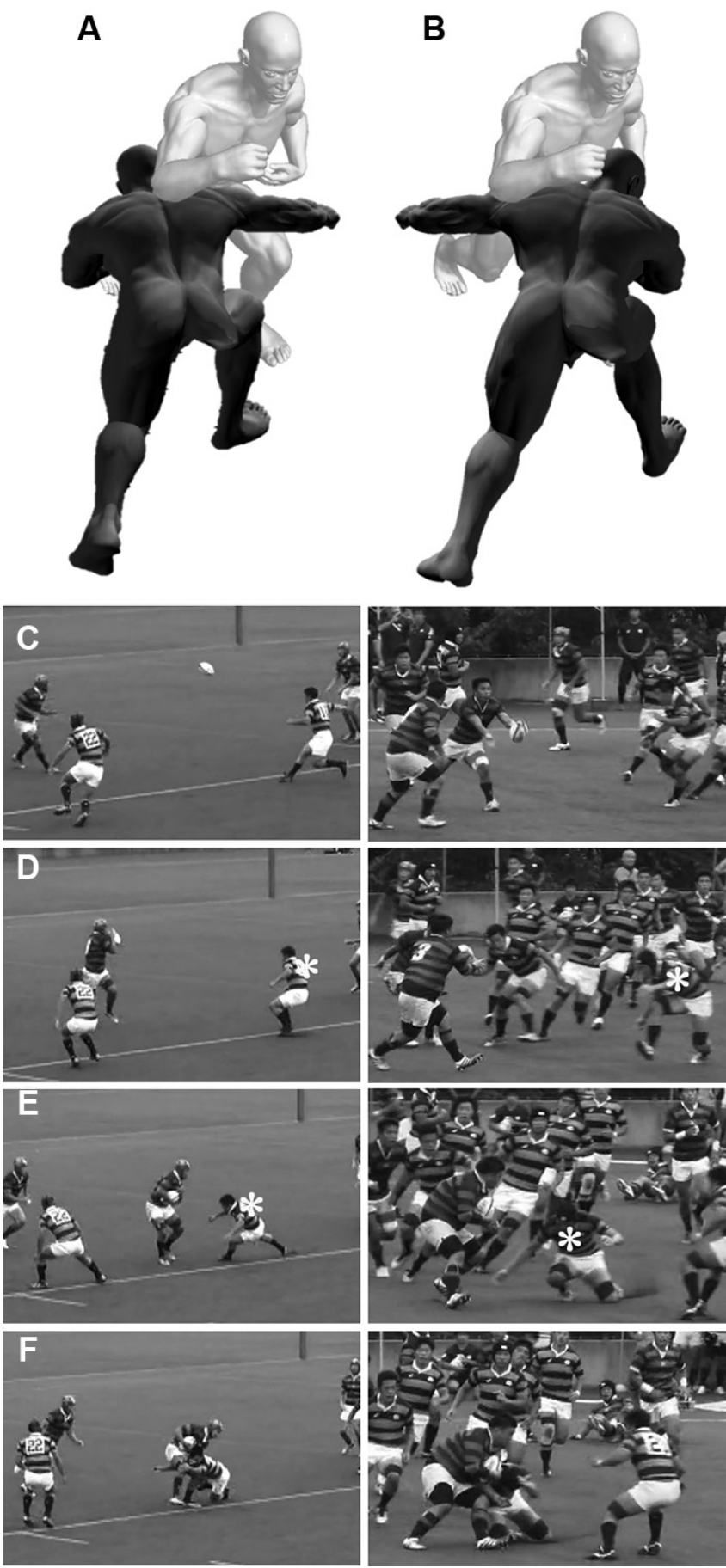

Figure 1 Definitions of one-on-one tackles. (A) Tackle with correct head positioning. (B) Tackle with incorrect head positioning. (C-F) Game video showing tackle with incorrect head positioning. (C) Before the player receives the ball. (D) Start of ball possession by the ball carrier (start of the precontact phase). (E) Tackler approaches the ball carrier. (F) Tackler contacts the ball carrier (end of the precontact phase). *Tackler.

applied to compute the $\mathrm{P}$ value because of a small sample size (less than 5) in several injuries.

The secondary analysis compared player positions (SteelDwass test) and injuries (Mann-Whitney U test) according to the duration and number of steps taken during (distance) the precontact phase. To understand the parameters related to injuries in the study population, ORs were calculated with logistic regression analysis. $\mathrm{P}<0.05$ was considered significant, and 
Table 1 Participants' characteristics $(n=317)$

\begin{tabular}{|c|c|}
\hline & Mean \pm SD $(95 \% \mathrm{Cl})$ \\
\hline Age (years) & $19.8 \pm 1.3$ (19.6 to 20.0$)$ \\
\hline Height $(\mathrm{cm})$ & $174.3 \pm 5.9(173.6$ to 175.1$)$ \\
\hline Weight (kg) & $86.9 \pm 10.0$ (85.6 to 88.1 ) \\
\hline BMI & $28.6 \pm 2.9(28.2$ to 28.9$)$ \\
\hline Experience (year) & $12.2 \pm 3.3$ (11.8 to 12.6$)$ \\
\hline Position & N (\%) \\
\hline Front row & $58(18.3)$ \\
\hline Lock & $26(8.2)$ \\
\hline Back row & $104(32.8)$ \\
\hline Scrum half & $22(6.9)$ \\
\hline Fly half & $32(10.1)$ \\
\hline Inside backs (СТB) & $44(13.9)$ \\
\hline Outside backs (WTB and FB) & $31(9.8)$ \\
\hline
\end{tabular}

$\mathrm{BMI}$, body mass index; $\mathrm{CTB}$, centre three quarter backs; $\mathrm{N}$, number of

participants; WTB, wing.

all tests were two sided. Data analysis was conducted with the free software R (The R Foundation for Statistical Computing, Vienna, Austria) and the SPSS software program for Macintosh V.21.0 (IBM, Chicago, IL, USA).

\section{RESULTS}

The percentage of evaluator agreement, representing inter-rater reliability, in our evaluation of tackle categorisation was $97.4 \%$; the kappa coefficient was 0.94 . These values were sufficient to perform our main research.

In total, 3970 tackles from 28 games, including 317 (8.0\%) tackles with the head incorrectly positioned, were investigated. The characteristics of the tacklers with incorrect head positioning are summarised in table 1 . Thirty-two head, neck and shoulder injuries (32/3970; injury frequency $0.8 \%$ ) were analysed. The incidence of injury during tackles with incorrect head positioning was 69.4 per 1000 tackles. The incidence of injury during tackles with correct head positioning was 2.7 per 1000 tackles. The $\chi^{2}$ test demonstrated that incidence of concussion, neck injuries, stingers and nasal fractures was significantly higher during tackles with incorrect head positioning than during tackles with correct head positioning (table 2).

In the game video analysis, duration and number of steps taken during the precontact phase were significantly different for players in different team positions $(\mathrm{P}<0.05)$. Outside backs took more steps during the precontact phase than front row and lock players. Furthermore, the duration of the precontact phase was significantly longer for outside backs than for front row players (figure 2). Additionally, significantly fewer steps were taken during the precontact phase of tackles that resulted in injury than before tackles that did not result in injury $(\mathrm{P}<0.05)$. Tackles that resulted in injuries also tended to be shorter in duration than those that did not result in injuries (table 3).

The questionnaire responses of the tacklers who had incorrect head positioning are summarised in table 4 . In $13.9 \%$ of these players (44/317), the incorrect head positioning was intentional. Their reasons for tackling with incorrect head position included habit, protection of the tackler's injured shoulder and because the ball carrier did not stop. Sixty-one per cent of players (193/317) reported that they could have prevented their head from contacting the front of the ball carrier. The results showed no correlation between tackler's intention and the incidence of injury.

\section{DISCUSSION}

Concussions, neck injuries, stingers and shoulder injuries most commonly occur in rugby during tackling ${ }^{19-13}$; thus, detailed research into prevention strategies is required. Despite several interventions, including changes to tackle techniques and exercises aimed at reducing injury, no prevention strategy has been established. ${ }^{1819}$ In this study, we investigated one-on-one tackles that were identified from approximately 4000 tackles in game videos. The incidence of head, neck or shoulder injury was $0.8 \%$ (32/3970). In previous studies, Mcintosh et al ${ }^{29}$ reported a rugby injury incidence of $1.2 \%(81 / 6618)$, while Fuller et al $l^{30}$ reported an incidence of 3.9\% (244/6219). However, both of those studies included all injuries. In an investigation of injury incidence, Quarrie and Hopkins categorised tackles by height as head/neck, high, middle or low. ${ }^{28}$ That study concluded that low tackles had a higher risk of injury. In football, headdown contact and spearing were reported to increase the risk of cervical spine injury; therefore, football rules, education and coaching were altered to dramatically reduce these incidents. ${ }^{20}$ World Rugby, the New Zealand Rugby Union and the Australian Rugby Union currently recommend as a key point that the tackler's head be positioned behind or to one side of the ball carrier when tackling. ${ }^{21-23}$ Tackling with incorrect head positioning is not recommended to avoid direct impact; however,

Table 2 Incidence of injury according to tackle type

\begin{tabular}{|c|c|c|c|c|c|c|c|}
\hline & Injury & $\begin{array}{l}\text { Total, } \mathrm{n} \\
\text { (/1000 tackles) }\end{array}$ & $\begin{array}{l}\text { Concussion, } \mathrm{n} \\
\text { (/1000 tackles) }\end{array}$ & $\begin{array}{l}\text { Neck injury, } \mathrm{n} \\
\text { (/1000 tackles) }\end{array}$ & $\begin{array}{l}\text { Stinger, } \mathrm{n} \\
\text { (/1000 tackles) }\end{array}$ & $\begin{array}{l}\text { Shoulder injury, } \mathbf{n} \\
\text { (/1000 tackles) }\end{array}$ & $\begin{array}{l}\text { Nasal fracture, } \mathrm{n} \\
\text { (/1000 tackles) }\end{array}$ \\
\hline \multirow{2}{*}{$\begin{array}{l}\text { Tackle with incorrect } \\
\text { head position }\end{array}$} & + & $22(69.4)$ & $10(31.5)$ & $3(9.5)$ & $12(37.9)$ & $1(3.2)$ & $2(6.3)$ \\
\hline & - & 295 & 307 & 314 & 305 & 316 & 315 \\
\hline \multirow{2}{*}{$\begin{array}{l}\text { Tackle with correct head } \\
\text { position }\end{array}$} & + & $10(2.7)$ & $4(1.1)$ & $1(0.3)$ & $4(1.1)$ & $0(0)$ & $1(0.3)$ \\
\hline & - & 3643 & 3649 & 3652 & 3649 & 3653 & 3652 \\
\hline Degree of freedom & & 1 & 1 & 1 & 1 & 1 & 1 \\
\hline Pearson $\chi^{2}$ value & & 162.1 & 77.0 & 24.5 & 87.5 & 11.5 & 14.1 \\
\hline Continuity correction & & 153.9 & 68.5 & 16.2 & 89.3 & 2.4 & 7.2 \\
\hline Likelihood ratio & & 74.5 & 34.7 & 10.9 & 43.7 & 5.1 & 6.5 \\
\hline Fisher's exact test, $\mathrm{P}$ & & $<0.01 *$ & $<0.01$ * & $<0.01$ * & $<0.01$ * & 0.08 & $0.02 *$ \\
\hline Phi coefficient & & 0.20 & 0.14 & 0.08 & 0.16 & 0.05 & 0.06 \\
\hline OR $(95 \% \mathrm{Cl})$ & & 27.2 (12.7 to 57.9$)$ & 29.7 (9.3 to 95.3$)$ & 34.9 (3.6 to 336.4$)$ & $35.9(11.5$ to 112.0$)$ & $\mathrm{NE}$ & $23.2(2.1$ to 256.4$)$ \\
\hline Power of analysis & & 1.0 & 0.99 & 0.72 & 1.0 & $\mathrm{NE}$ & 0.54 \\
\hline
\end{tabular}

*Significance.

$\mathrm{NE}$, not estimated. 


\section{Original article}
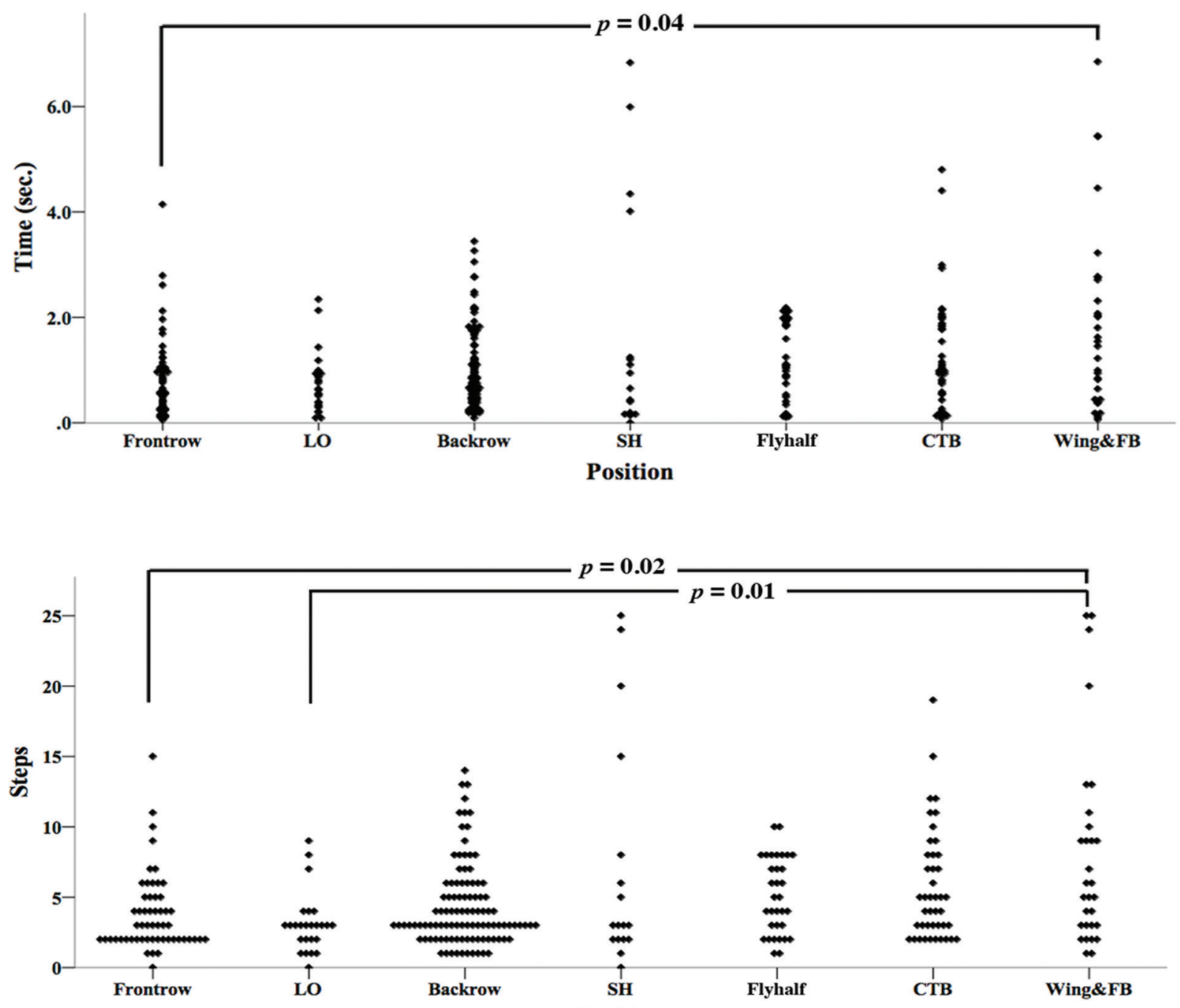

Position

Figure 2 Duration of and number of steps taken during precontact phase according to player position. CTB, center three-quarter back; FB, full back; LO, lock; SH, scrum half.

injury frequency and incidence in this context have not been reported. In 2016, Tierney et al ${ }^{24}$ classified the head placement of tacklers as in front of, on the side of or behind the ball carrier and concluded that direct head impact is most often caused by head placement in front of the ball carrier. However, the incidence of injury has not been investigated. In 2017, Tucker et $\mathrm{al}^{25}$ reported that high-energy transfers such as front-on tackles and tackles involving acceleration and speed were more injurious than other tackles. However, the tackler's head placement was not mentioned in that study.

This is the first study to categorise tackles into two types according to tackler's head position, and to investigate the associations between head position and injuries of the head,

\begin{tabular}{|c|c|c|c|}
\hline \multirow[b]{2}{*}{ Variable } & \multicolumn{2}{|c|}{ Injury } & \multirow[b]{2}{*}{$\mathbf{P}^{*}$} \\
\hline & + & - & \\
\hline Duration of precontact phase (seconds, median) & 0.43 & 0.85 & 0.07 \\
\hline Distance of precontact phase (steps, median) & 3 & 4 & $0.04 \dagger$ \\
\hline
\end{tabular}

neck and shoulder. The study provides novel findings. Approximately $10 \%$ of tackles (317/3970) occurred with the tackler's head positioned incorrectly in front of the ball carrier; injury incidence rates were significantly higher for tackles with incorrect head positioning than for other tackles. In addition, we analysed the circumstances of tackles, focusing on the precontact phase to investigate its characteristics and its relationship to injury incidence according to player's position. The precontact phase varied widely, meaning that the tackle occurred in a

\begin{tabular}{|cc}
\hline Table 4 & Causes of tackles with incorrect head positioning $(\mathrm{n}=317)$ \\
\hline Intentional & $13.9 \%$ \\
\hline Habitual side for tackling & $6.6 \%$ \\
\hline To protect tackler's injured shoulder & $0.3 \%$ \\
\hline The ball carrier does not stop. & $6.9 \%$ \\
\hline Unintentional & $73.5 \%$ \\
\hline Accidental & $38.5 \%$ \\
\hline The ball carrier directly faces the tackler. & $14.8 \%$ \\
\hline The ball carrier changes direction. & $11.0 \%$ \\
\hline Distance required for tackling is misjudged. & $9.1 \%$ \\
\hline None of the above/other reasons & $12.6 \%$ \\
\hline
\end{tabular}


variety of circumstances. These characteristics were described for all positions, with the characteristics of the precontact phase for outside backs notably different from those of all other positions. The outside backs took more steps during the precontact phase than the front row and lock players, and the duration of the precontact phase was significantly longer for outside backs than for front row players. The precontact phase was defined as the time and space in which a tackler sees, recognises and acts on (tackles) the ball carrier. Outside backs who took more steps had the time to choose their action (tackling) through sight and recognition, and could therefore avoid tackling with their head incorrectly positioned. Conversely, front row and lock players who took fewer steps did not have the time to choose their action (tackling) through sight and recognition. Rather, they needed to apply preventive strategies before the precontact phase, for example, changing their standing position relative to opposing players (ie, not facing directly towards the ball carrier) and imagining tackling with their head on the correct side from any direction from which the ball carrier advanced. Thus, different preventive strategies are required for each position. When tackling with incorrect head positioning, injuries were incurred by players in all positions; however, significantly fewer steps were taken by the ball carrier during the precontact phases of tackles that resulted in injury than of those who did not. Our findings suggest that players with a shorter precontact phase and who tackled with incorrect head positioning received direct impact on their head or neck as a result of incomplete positioning, which resulted in a higher incidence of head and neck injury. To prevent these injuries, tacklers should use the above strategies to avoid incorrect head positioning.

Many interesting responses were noted on the questionnaire. In $13.9 \%$ of 317 tackles, incorrect head positioning was intentional. The reasons tacklers reported for the incorrect head positioning included habit, protection of tackler's injured shoulder and because the ball carrier did not stop. Additionally, $61.0 \%$ of the players said they could avoid tackling with incorrect head positioning. Although no correlation was found between the player's intentions and the incidence of injury, the injury incidence is expected to differ by player, for specific reasons. When asked, each player provided recommendations to prevent risky tackles with incorrect head positioning.

Although the current study revealed important data, as described above, several limitations should be addressed. First, the study had a small sample size that included two teams that played over two seasons. Differences in the teams' levels, tactics and coaching methods for tackle skills in each season may have introduced bias in injury occurrence. In addition, because of the small sample size consisting only of collegiate players, the results might not be generalisable to all rugby players. Further clinical studies and long-term observations in larger populations are needed to confirm our findings. Second, the videos analysed were recorded from a single angle, which might have resulted in error. However, we think that this limitation did not greatly influence our results because the interobserver reliability was high. Third, the questionnaire and injury data may be inaccurate. Regarding the measurement properties of our questionnaire, content and structural validity as well as interpretability were not tested in the present study. However, players answered the questionnaire while watching video within 1 week after a match, which likely improved accuracy. Regarding the accuracy of the injury data, all injuries were completely followed because they were evaluated immediately after the match and again the next day by the team physiotherapist or doctor.
What are the findings?

- This is the first study to categorise tackles into two types according to the tackler's head position, and to investigate the relationship between head position and injuries of the head, neck and shoulder.

- Tackles with incorrect head positioning, meaning that the tackler's head is in front of the ball carrier, have a significantly higher incidence of injury, including concussions, neck injuries, stingers and nasal fractures, than tackles made with correct head positioning, meaning that the tackler's head is positioned behind or to one side of the ball carrier.

- The present findings also suggest that tackles preceded by a shorter time and distance travelled before contact tended to result in more injuries.

How might it impact on clinical practice in the future?

- The present observational study provides evidence that tackles with incorrect head positioning have a significantly higher injury incidence than tackles with correct head positioning.

- This finding should be included in the education of rugby coaches and players.

\section{CONCLUSIONS}

In this epidemiological study, we evaluated and categorised the tackler's head position relative to the ball carrier during one-on-one tackling. We also described the incidence of head, neck and shoulder injuries using game video analysis, injury records and a questionnaire completed by the actual tacklers. Tackles with incorrect head positioning were associated with a significantly higher incidence of concussions, neck injuries, stingers and nasal fractures. Injuries tended to occur more often when tackles were of shorter duration and when there was shorter distance covered before contact. The circumstances of tackling differed for each player position; several prevention strategies are needed for each position. Additionally, $61.0 \%$ of players reported that they were able to prevent a tackle with incorrect head positioning. These findings provide important information that can greatly reduce the incidence of head and neck injuries and that should be included in the education of rugby coaches and players.

Correction notice This article has been corrected since it was published Online First. The name of author Chihiro Ota has been corrected.

Acknowledgements We thank Keio University Rugby Football Club, Meiji University Rugby Football Club, Yuki Nakamura, Ayaka Shishido, Moeko Ogino, Nonoka Sugaya, Tomoki Ohno, Yasumasa Tanabe, Shota Hoshika, Yuki Miyasaka, Tomoyuki Mochizuki, Toshinari Akimoto and Masashi Nagao for their valuable help with this study. We also thank Rebecca Tollefson, DVM, from Edanz Group (www. edanzediting.com/ac) for editing a draft of this manuscript.

Contributors SS and TK contributed equally to this work. TK: supervisor of SS, designed and planned the study. SS and TK performed data analysing and wrote the initial draft of the manuscript. All other authors have contributed to data collection and interpretation, and critically reviewed the manuscript. All authors approved the final version of the manuscript, and agree to be accountable for all aspects of the work in ensuring that questions related to the accuracy or integrity of any part of the work are appropriately investigated and resolved.

Competing interests None declared.

Patient consent Obtained. 
Ethics approval The study was approved by our hospital's institutional review board Juntendo University Faculty of Medicine (number 14-161).

Provenance and peer review Not commissioned; externally peer reviewed.

Open Access This is an Open Access article distributed in accordance with the Creative Commons Attribution Non Commercial (CC BY-NC 4.0) license, which permits others to distribute, remix, adapt, build upon this work non-commercially, and license their derivative works on different terms, provided the original work is properly cited and the use is non-commercial. See: http://creativecommons.org/ licenses/by-nc/4.0/

(c) Article author(s) (or their employer(s) unless otherwise stated in the text of the article) 2018. All rights reserved. No commercial use is permitted unless otherwise expressly granted.

\section{REFERENCES}

1 Bathgate A, Best JP, Craig G, et al. A prospective study of injuries to elite Australian rugby union players. Br J Sports Med 2002;36:265-9.

2 Willigenburg NW, Borchers JR, Quincy R, et al. Comparison of injuries in American collegiate football and club rugby: a prospective cohort study. Am I Sports Med 2016;44:753-60.

3 Brooks JH, Kemp SP. Recent trends in rugby union injuries. Clin Sports Med 2008;27:51-73.

4 Quarrie KL, Cantu RC, Chalmers DJ. Rugby union injuries to the cervical spine and spinal cord. Sports Med 2002;32:633-53.

5 Reboursiere E, Bohu Y, Retière D, et al. Impact of the national prevention policy and scrum law changes on the incidence of rugby-related catastrophic cervical spine injuries in French Rugby Union. Br J Sports Med 2016;0:bjsports-2016-096122.

6 Hendricks S, Lambert MI, Brown JC, et al. An evidence-driven approach to scrum law modifications in amateur rugby played in South Africa. Br I Sports Med 2014;48:1115-9.

7 Cazzola D, Preatoni E, Stokes KA, et al. A modified prebind engagement process reduces biomechanical loading on front row players during scrummaging: a crosssectional study of 11 elite teams. Br J Sports Med 2015;49:541-6.

8 Preatoni E, Stokes KA, England ME, et al. Engagement techniques and playing level impact the biomechanical demands on rugby forwards during machine-based scrummaging. Br J Sports Med 2015;49:520-8.

9 Rihn JA, Anderson DT, Lamb K, et al. Cervical spine injuries in American football. Sports Med 2009;39:697-708.

10 Archbold HA, Rankin AT, Webb M, et al. RISUS study: rugby injury surveillance in ulster schools. Br J Sports Med 2017;51:600-6.

11 Freitag A, Kirkwood G, Scharer S, et al. Systematic review of rugby injuries in children and adolescents under 21 years. Br I Sports Med 2015;49:511-9.
12 Horsley IG, Fowler EM, Rolf CG. Shoulder injuries in professional rugby: a retrospective analysis. J Orthop Surg Res 2013;8:9.

13 Wilson BD, Quarrie KL, Milburn PD, et al. The nature and circumstances of tackle injuries in rugby union. J Sci Med Sport 1999;2:153-62.

14 Gerrard DF. The use of padding in rugby union. Sports Medicine 1998;25:329-32.

15 Marshall SW, Loomis DP, Waller AE, et al. Evaluation of protective equipment for prevention of injuries in rugby union. Int J Epidemio/ 2005;34:113-8.

16 McCrory P. Do mouthguards prevent concussion? Br I Sports Med 2001;35:81-2.

17 Laws of the Game Rugby Union. Dangerous tackles (high tackles). http://laws. worldrugby.org/?domain=9\&guideline=3\&language $=E N$ (accessed 2 June 2017).

18 Burger N, Lambert MI, Viljoen W, et al. Tackle technique and tackle-related injuries in high-level South African Rugby Union under-18 players: real-match video analysis. $\mathrm{Br} \mathrm{J}$ Sports Med 2016;50:932-8.

19 Attwood M, Roberts S, Trewartha G, et al. Efficacy of a movement control injuryprevention programme in an adult community rugby union population; a cluster randomised controlled trial. Br J Sports Med 2017;51:1-290.

20 Heck JF, Clarke KS, Peterson TR, et al. National Athletic Trainers' Association Position Statement: Head-Down Contact and Spearing in Tackle Football. J Athl Train 2004;39:101-11.

21 World Rugby. Rugby Ready. http://rugbyready.worldrugby.org/index.php?section=65_ 1\&tab=tab-4 (accessed 2 June 2017).

22 Australian Rugby. Smart Rugby. http://www.aru.com.au/portals/23/ebooks/2016/ mobile/index.htm|\#p=24 (accessed 2 June 2017).

23 New Zealand Rugby. Rugby Smart. https://www.coachingtoolbox.co.nz/rugbysmart/ player-s-rugbysmart/tackle-technique (accessed 2 June 2017).

24 Tierney GJ, Lawler J, Denvir K, et al. Risks associated with significant head impact events in elite rugby union. Brain Inj 2016;30:1350-61.

25 Tucker R, Raftery M, Kemp S, et al. Risk factors for head injury events in professional rugby union: a video analysis of 464 head injury events to inform proposed injury prevention strategies. Br J Sports Med 2017;51:1152-7.

26 Fuller CW, Molloy MG, Bagate C, et al. Consensus statement on injury definitions and data collection procedures for studies of injuries in rugby union. Br J Sports Med 2007:41:328-31

27 Kawasaki T, Ota C, Yoneda T, et al. Incidence of Stingers in Young Rugby Players. Am J Sports Med 2015;43:2809-15.

28 Quarrie KL, Hopkins WG. Tackle injuries in professional Rugby Union. Am J Sports Med 2008;36:1705-16.

29 McIntosh AS, Savage TN, McCrory P, et al. Tackle characteristics and injury in a cross section of rugby union football. Med Sci Sports Exerc 2010;42:977-84.

30 Fuller CW, Ashton T, Brooks JH, et al. Injury risks associated with tackling in rugby union. Br J Sports Med 2010;44:159-67. 